\title{
f \\ ASPECTS OF THE DIAGNOSIS AND TREATMENT OF THE CHRONIC COUGH
}

\author{
By C. H. FrTTs, M.D., F.R.C.P., F.R.A.C.P. \\ Physician, Royal Melbourne Hospital
}

What is a cough? Sir Thomas Browne in $165^{\circ}$ defined coughing as a natural and voluntary motion including expectoration and spitting out. ' It may,' he said, ' be as proper unto mankind as bleeding at the nose.' The definition occurs in a letter of condolence to a friend, which broadens into a clinical and philosophical dissertation on cough and phthisis. On seeing the patient in his last illness, Sir Thomas gave the prognosis to the relatives 'that in my sad opinion, he was not like to behold a grasshopper, much less to pluck another fig.'

The Oxford Dictionary defines cough as a violent expulsion of air from the lungs with a characteristic noise. R. A. Young (I940) described cough as a sensitive reserve mechanism to deal with any abnormal increase of fluid in the air passages and with foreign bodies. Chevalier Jackson (r933) called the cough reflex the watchdog of the lung. This places the right emphasis on the role of cough which is to prevent entrance of noxious agents rather than to provoke their exit.

The afferent paths by which this reflex may be initiated are widespread. The most important are through the sensory branches of the glossopharyngeal nerve to the pharynx and the vagal branches of the larynx, trachea and bronchi. The reflex diminishes as the bronchial tree ramifies and is absent in the finer bronchioles and alveoli. The reflex appears to be quite active, however, if the pleura is inflamed and pain is present. Stimulation of the central end of the superior laryngeal nerve causes reflex swallowing as well as cough. Perhaps for this reason the gastric mucus may sometimes be the best source for tubercle bacilli when pulmonary tuberculosis is suspected.

Cough is composed of three distinct phases (Coryllos, 1937). These are inspiratory, compressive and expulsive. Each of these presents special physiological characteristics. Though it can be started voluntarily it is almost as impossible to stop a cough after a certain stage as to stop deglutition, micturition, vomiting or sneezing.
The first or inspiratory phase is short. In this the glottis is closed whilst a mounting pressure is raised in the chest up to 80 or even $100 \mathrm{~mm}$. of mercury. A study of the movement of the chest by cinematography during the cough gives the impression during inspiration of a process akin to the tensing of a strong bow, and the quick spring back with the onset of expiration heightens this impression (Franklin and Janke, 1938).

The second or compressive stage marks the beginning of expiration. The important expiratory muscles are abdominal. Under their influence the capacity of the chest is reduced by the downward movement of the ribs and sternum. Thus pressure is exerted upon the air imprisoned in the lungs by the closure of the glottis. The diaphragm contracts in this stage, giving a rigid floor to the thoracic cage and preventing the thrust of the abdominal viscera into the chest.

Cough is a physical effort and, on reflection, it is apparent that inspiration and compression are common components of many different types of effort. Singing, laughing and crying are examples. On what slender emotional threads sometimes hangs the decision as to which path expression will take.

In the third, or expulsive phase, the glottis is opened and successive contractions of the abdominal muscles take place. Nature does not take a sledge hammer to crack a nut. The abdominal contractions vary in force and magnitude according to the real or imagined resistance which has to be overcome in the bronchial tree. Again the diaphragm contracts and acts as the antagonist to the abdominal muscles. The velocity of the blast of air passing through the glottis has been estimated to reach 30 miles per hour, and those who have stood in its path might not think it fanciful to compare it to a gale.

Physical signs in respiratory diseases provide precarious means for diagnosis and it is worth remembering the physiological and pathological antecedents of cough. They add point to the 
analysis of the history. In an American study of undiagnosed cough in 200 patients (Voorsanger and Firstone, 1927) a list is given of the pathological conditions causing cough, This includes pulmonary fibrosis, emphysema, sinusitis, tonsillitis, thyroid insufficiency and enlarged bronchial root glands. Why should pulmonary fibrosis or emphysema cause cough? Neither will do so unless there is an associated bronchitis to excite the cough reflex. Why does the so-called dry bronchiectasis remain a silent disease unless the patient coughs up blood? Because it is in a region where the sensory paths of the cough reflex do not penetrate. Why does the patient with wet bronchiectasis sleep peacefully in his bed at night? Because the secretion lies undisturbed in the insensitive saccules. On rising in the morning the sputum is splashed into the sensitive larger tubes and the patient coughs and only ceases for lack of sputum. One might make a generalization from this. Beyond a certain point in the bronchial tree, cough is not a symptom unless sputum or blood, hydatid or other fluid is able to move from its source to an area where the reflex can be initiated. Tuberculosis, carcinoma of the lung parenchyma, lung abscess and silicosis are examples of diseases of the lung substance in which there is no cough until there is material to be evacuated. It is a common experience to find that a foreign body having passed beyond the frontier of the protective cough reflex will lie unheeded in the finer divisions of the bronchial tree until infection brings purulent sputum to excite the cough reflex and draw attention to its presence. The evacuation of purulent secretion or blood from a lung abscess or a tuberculous cavity by means of cough may not be complete. If one observes the fate of lipiodol instilled into the bronchial tree it will be seen that a cough that does not expel it may be followed by another cough, and in the inspiratory phase the oil is drawn into the alveoli. If the material is pus rather than lipiodol then a spread of infection may ensue. This may be the mechanism of the bronchogenic spread of tuberculosis. The term 'spill-over' is graphic, but perhaps it is too simple an explanation of the spread of infection in healthy tissue. It follows from what has been said that the bifurcation of the trachea and not the mouth should be the target of postural drainage. Once get the secretion to this area and the cough reflex will do the rest.

If diseases of the finer bronchioles and the lungs do not produce cough unless there is sputum to evacuate, the converse is true that inflammation or irritation in the larynx, trachea or larger bronchi and, indeed, stimulation of afferent nerves in the pharynx or stomach will produce a cough with little or no sputum. These are the territories of the dry cough. The paroxysms of whooping cough or of what is loosely termed 'virus infection' are examples of the unproductive cough. $\frac{3}{8}$ The distinctive characteristics of the cough of $\stackrel{\square}{2}$ tuberculous laryngitis, of laryngeal palsy and of $\overline{.}$ mediastinal pressure are well known.

There are certain features about cough which $\stackrel{\overrightarrow{7}}{\rightarrow}$ should be sought in taking the history. The first $\frac{0}{0}$ of these is the time of occurrence. The morning $\frac{\bar{D}}{\bar{\omega}}$ cough of bronchiectasis has been mentioned. $\vec{\nabla}$ Lovett Doust and Schneider (1952), in a study of $\propto$ anoxia and the levels of sleep, observed that with is light sleep and deep sleep the arterial oxygen $\overrightarrow{0}$ saturation lay between 91 per cent. and 87 per cent. $\vec{\overrightarrow{ }}$ They describe these as the noisy periods of sleep; $\vec{\sigma}$ groaning, mumbling, grunting, gasping, snoring, sighing and sometimes coughing being individually representative responses for any given subject. Each of these activities is closely correlated with oximetric changes. A child may sleep through of cough and fever whilst his parents burn with $\vec{i}$ anxiety in the next room. None the less, it is well $\circ$ to regard nocturnal cough as being associated with $\overrightarrow{ }$ asthma until proved otherwise. A cough during $\vec{c}$ working hours may be due to the real or supposed hazards of industry. The fumes of chemicals may be unpleasant but harmless. Yet once sow the seeds of doubt in a worker of unstable temperao ment and he becomes convinced that his lungs are being damaged. The really dangerous substances are silica dusts: The particles which cause the damage are less than ten microns in size, do not provoke cough and so penetrate to the recesses of the alveoli. Irritant gases may provoke or aggravate a bronchitis. One cannot overcome these problems with gas masks nor by any means that depend on the wishes or attention of the workman. A cough may be periodic, quite apart from clinical or seasonal variations. An example of this is furnished by lung abscess. With the evacuation of the abscess contents, the temperature falls and improvement occurs. After a time the cough and sputum may diminish to nothing. By this time the temperature is slowly rising to fall again when the abscess, which has pocketed, ruptures and cough and sputum return.

Some people complain of a cough chiefly or only when in the recumbent position. This is not quite the same as a nocturnal cough. I have seen $\tilde{\sigma}$ young people complain of an irritating dry cough $N$ who, when placed in the recumbent position for $N_{\mathcal{E}}$ examination, involuntarily sit up because of the onset of cough. I think the cause is sometimes to be found in the personality of the patient.

A second point of enquiry should be for the $\stackrel{\mathscr{D}}{\rightarrow}$ presence and the character of sputum and the amount which should be measured. The sudden evacuation of a quantity of purulent sputum can mean only the rupture of a lung abscess or of an 
empyema into a bronchus. Let it-never be forgotten that the sputum accompanying any chronic cough should be examined repeatedly for the mycobacteria of tuberculosis.

Thirdly, one should ask whether blood has been coughed up and in what quantity. It is not merely academic to probe the distinctions between haemoptysis and haematemesis. The person who coughs blood commonly has blood-stained sputum during the succeeding days. There are times apparently when the threshold of excitation of the cough reflex is not crossed by what would seem to be more than adequate stimuli. I am thinking of patients who say that blood or hydatid fluid welled into the mouth without the preliminary aid of cough. Conversely, a patient may deny a cough but admit that he has sputum, and it cannot be taken for granted that there is no sputum if there is no cough.

Fourthly, it is wise to enquire whether there is wheezing as well as cough. Very few asthmatics do not wheeze and most people who do wheeze have asthma. Many asthmatics pass unrecognized because of the failure to recognize the periodic nature of the cough, to ask for the presence of wheezing and through a too rigid belief that asthma manifests itself only by the classical attack.

Most, but not all, people who wheeze have asthma. Sufferers from pulmonary tuberculosis may wheeze and present as asthmatics when, in actual fact, the wheezing is due to tuberculous bronchitis with stenosis. People with emphysema develop bronchial spasm during the course of their disease. Too often the emphysema is regarded as secondary to asthma when, in fact, the spasm comes comparatively late in the course of the disease. In the course of mitral stenosis with pulmonary hypertension the patient may complain of cough and wheezing dyspnoea.

Lastly, it is to be remembered that the issue may be confused by a number of possible causes for cough existing in one person and that prominence given to the cough by the patient in stating his case may lead to a false estimate of its importance. A man of 60 may complain of cough and purulent sputum. The history and perhaps the physical signs suggest that he has chronic bronchitis, but the cough and dyspnoea are at their worst at night. The patient wheezes. His blood pressure is high. Is one to conclude that his nocturnal dyspnoea and cough are due to bronchitis, to bronchial asthma or to cardiac asthma? More often than not I believe the nocturnal dyspnoea is due to left heart failure and that the best treatment for both the cough and the dyspnoea may be the relief of congestion by digitalis and diuretics. Patients with congestive heart failure may be greatly distressed by a cough with a desire to expectorate some secretion from the region of the larynx or trachea. The expectoration of a little mucus brings a very temporary relief. Relief of the cardiac failure is often more fruitful than mędication directed to the cough.

\section{Treatment}

What of the treatment of cough? Remedies for cough seem only less popular than purgatives for constipation. The latter is not subject to seasonal variations and while it is difficult to maintain cough by means of a mixture it is easy to perpetuate constipation with a pill. There are numerous expectorants all of doubtful value, though connoisseurs (Boyd and MacLachlan, 1944) state that paregoric which has been allowed to mature for three years is superior to others. Though there are objections to the use of sedatives, on the whole they are more useful than expectorants. No theoretical objections should deny morphia to a patient suffering the alarming experience of a $\vec{i}$ serious haemoptysis, nor do I think I have cause to regret its judicious use in pneumonia. A linctus may provide the only solace from a racking cough. It is described by the Oxford Dictionary as a syrupy medicine to be licked up with the tongue. It should be treated with a certain respect and retained in the mouth for a time before swallowing Though not as rewarding as old brandy, attentio to this may enhance the action of the linctus. would put in a plea for a neglected drug - valerian The ammoniated tincture of valerian in combination with bromide is a valuable preparation when a patient is nauseated by food and inclined to retch with coughing. It is best given before meals. Bed rest and silence may be excellent sedatives. Inhalants and steam kettles are soothing and perhaps even have a psychological effect. Aerosol inhalation of antibiotics is out of fashion and I think rightly so. Wool, red flannel and thermogene next to the skin, camphor worn as an amulet, close stuffy atmospheres are all met with even in these days. Sir Thomas Browne remarked that "The ancient inhabitants of this island were less troubled with coughs when they went naked and slept in caves and woods than men in chambers and feather beds.'

Expectorants, sedatives, charms and amulets have given place to the use of antibiotics. Ostensibly justified because of the presence of infection, often they are given because the patient complains bitterly of his cough. We are in no position to laugh at our predecessors.

As cough is under the control of the will so it may be the expression of an emotional disturbance. Some people do not know whether to laugh or to cry and evade the dilemma by coughing. Politicians and public speakers are not above a paroxysm in moments of difficulty, and warning, disapproving 
and apologetic coughs are the stock-in-trade of the novelist and playwright. What a powerful weapon a cough can be in the throat of a neurotic person! I cannot uncover the mystery whereby the neurotic soldier of the 1914-18 war developed effort syndrome and of the. recent war dyspepsia, when one thinks of the havoc that can be wrought by coughing.

Coughs have been divided into productive and unproductive and into useful and useless. Yet at times nothing could be more fruitful than a useless unproductive cough. It can be produced by a healthy person of his own volition. If, however, the stimulus be strong enough, a person with laryngitis, tracheitis or bronchitis will cough despite himself. On the other hand the sufferer may exercise some choice. The cough is halted in the compressive stage. so as to avoid drowning the parson's saws. Mark, too, how the veriest novice at an orchestral concert synchronizes his expulsive blast as the conductor brings in the percussion or the brass. Some of these coughs are unnecessary even in people who have some organic disorder. The secret lies in self control which must be exercised before the glottis is closed for compression. One sees a hint of this in the rather free inspiration and expiration of a person endeavouring to overcome a desire to cough.

Years ago (1876) Charcot described a condition which he called laryngeal vertigo. It occurs most frequently in middle-aged males and is associated with largyngitis or bronchitis. There may be a personal or family history of epilepsy but this is not common. A frequent feature is an attack of dizziness or loss of consciousness preceded by a tickling sensation in the larynx and a cough which may be slight or severe. Epileptiform convulsions or movements may occur during the attack. Whitty (1943) regarded the majority of cases as being due to a true reflex epilepsy or epilepsy with a laryngeal aura. One of Whitty's patients had an attack following hearty laughter. The evidence in favour of epilepsy is not convincing. I have records of a patient whom I regarded as highly neurotic who could initiate a laryngeal cough by scratching behind his right ear. This area is supplied by the auricular branch of the vagus, sometimes called the nerve of Arnold. It is well known that stimulation of this nerve can initiate coughing.

I come now to a brief consideration of a few case histories which I think have a bearing upon the remarks I have made.

The first patient whom I shall mention I still recall after a lapse of years. She was a girl in her late 'teens living in London. She was referred to the throat department of the hospital for consideration of tonsillectomy as the possible source of an appalling cough of the useless unproductive variety. I remember the cough penetrating the consulting room door. Indeed the girl by means of her useless cough quickly displaced those ahead of her until she was allowed to see the throat surgeon long before her turn. I do not think I ever heard such a cough nor saw a victim less perturbed. It was decided that the tonsils were infected. She came into hospital and, of course, immediately after tonsillectomy her cough disappeared. She was asked to report progress in the outpatient department after some weeks had elapsed. On the day the noise of the approaching cough heralded her arrival in the department. I shall not weary you with detail, but her story was revealed eventually. Her father had remarried and she was the only child of the first marriage. The girl received scant recognition from her father under the new regime until she developed the cough. This conveyed to him the fear of tuberculosis and was sufficient to bring her the care and iv attention she had lacked. It was at her father's 을 instigation that she came to hospital. The moral of the story is that the justification for tonsillec-. tomy must lie in the presence of infection and not in the uncertain hope that it may banish a cough for which no obvious cause can be found.

The second history is that of a young man who was $3 I$ at the time of our meeting. He was dess cribed by his doctor in the following terms: ' $\mathrm{H}$. is known to most of his friends as the man with the cough. He is a troublesome kind of patient in $\overline{0}$

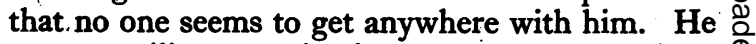
was on military service but was a worry to them $\mathbb{Q}$ from the time that he went in and was never well $\overrightarrow{\vec{P}}$ enough to be sent on active service. His cough $\frac{3}{3}$ annoys all his friends who know at once if he is at church or the pictures.' His story was illuminating. He began his working life on a farm and after $\bar{c}$ five years he gravitated to Melbourne. Since then 3 . he had never been any length of time in one job. $\frac{\dot{\sigma}}{3}$ He was in a dairy for 18 months, then at a spring factory, then on the assembly line at a motor body $\delta$ works where, after six months, he developed $₹$ pneumonia. He left that job and was in a woollen mill for three months. He then joined the Army and after a month developed pneumonia and was off duty for nine weeks. This period, I am sure, No was unnecessary and might have been considerably shortened. After that his legs began to 'play up' $O$ and he was labelled as having synovitis and asthma. N His worries when I' saw him were cough, pains in the limbs and a ' wonky' heart.

After full examination, including $X$-ray investigation of the chest, I could not fault him. $\mathrm{He} \stackrel{\oplus}{+}$ then told me some further details. He said that as a lad his attainments gave promise of a bright $\frac{\vec{D}}{\mathbb{D}}$

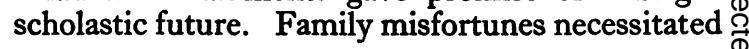


his leaving school at the age of 13 to help his parents. His elder sister remained at school. He remembered the very first occasion his cough was troublesome. It was at the school break-up after he had left and his sister was receiving a prize. Perhaps his cough began as a protest. Pathetically enough, I set him down as a slow-witted person whose intelligence was under average. Since his discharge from the Army he had, for the first time, freed himself from manual labour. He had not, however, freed himself from anxiety and he was attending night school to improve his position in a Government department where he had gained a precarious foothold as a temporary clerk. I tried to banish his fears of arthritis and heart disease. His cough seemed to me another matter and I do not know what obscure but useful purpose it might have served during 18 years.

The last example I shall give has to do with a single woman of 34 whose health had been good until the illness of which I speak. Her doctor said that this illness began with a cold three months before and he saw her after she had been ill for a month. She then had a temperature of 99.4 and a pleural friction rub in the left axilla. Her temperature became normal in a few days but she was left with a spasmodic cough at night which, he said, nothing would relieve except an injection of an opiate. An X-ray taken in the early stage of her illness brought a report that both lungs in the middle and lower zones showed accentuated bronchovascular markings and increased patchy density, suggesting incompletely resolved evanescent infection of the broncho-pneumonic type. There can be no doubt then that the patient had an obscure infection of the respiratory tract and one can only admire the restraint of her doctor and the radiologist, neither of whom ever introduced the word virus. The doctor's letter ended with the statement that she had, of course, had 'Potassium iodide and ammonium carbonate mixtures and all the Lincti (Linctuses) I could remember. She also had penicillin.' He then said he was going for a holiday.

When I saw her there were no abnormal signs in the chest, an X-ray film showed no abnormality and on screening there was no evidence of pleurisy though the movement of the diaphragm was negligible on both sides. In fact, inspection showed that she made very poor use of her ventilating apparatus.

I discovered that she had worked as a mail sorter at the G.P.O. on night shift because she had always slept badly at night. She had not worked for three months and had scarcely been out of the house in that time. Latterly she scarcely got out of bed. She had despaired of ever getting better and in the night panic drove her to ring her doctor for relief. Re-education in breathing and restoration of her confidence, for which an understanding physiotherapist must be given the credit, worked wonders in a fortnight and she then went away for a fortnight. She then resumed her occupation and has remained well since.

I have a conviction that the greatest benefit a doctor can confer on a fellow mortal is to give him back his independence as quickly as possible. I still remember with a shudder inheriting an invalid pensioner in my outpatient elinic. He had been attending for some years when I came. During all that time he took senega and ammonia. Cough mixtures do nothing of real value for a chronic cough. To teach a person how to use his breathing apparatus correctly and how to control his cough is, to some extent, to make him master of his own fate. An extra half hour spent on the investigation and explanation of a cough may save pints of cough mixture and much time. It may, indeed, save an operation, for the vaults of the mind may be more potent sources of cough than the crypts of the tonsil. More than one person is involved in a cough and an unfortunate child may be the victim of much unnecessary investigation and treatment for a cough that racks the parents and not the child.

It is demoralizing for patient and doctor to con-e tinue an association in which the only tie is a bottle? of medicine and beneath which lies a sense of failure.

To cure a cough sometimes it is necessary to accept the challenge to throw physic to the dogs and ask yourself:

' Canst thou not minister to a mind disease'd;

Pluck from the memory a rooted sorrow;

Raze out the written troubles of the brain;

And, with some sweet oblivious antidote,

Cleanse the stuff'd bosom of the perilous stuff,

Which weighs upon the heart?'

\section{BIBLIOGRAPHY}

BOYD, E. M., and MACLACHLAN, M. L. (1944), Canad, M.A.f. 50, 338.

BROWNE, SIR THOMAS (193I) 'Religio Medici and other Writings,' Everyman Edition, p. 149.

CHARCOT (1876), Gaz. Med. de Paris, 588; quoted by WHITTY (1943).

CORYLLOS, P. N. (1937), Amer. F. med. Sci., 194, 523.

DOUST, LOVETT, J. W., and SCHNEIDER, ROBERT A. (1952), Brit. med. Y., 449 .

FRANKLIN, K., and JANKER, R. (1938), f. Physiol., 92, 467.

JACKSON, C., and JACKSON, C. L. (1933), Amer. F. med. Sci., I86, 849 .

VOORSANGER, W. C., and FIRSTONE, F. (1927), Y.A.M.A., $89,1137$.

WHITTY, C. W. M. (1943), Brain, 66, 43.

YOUNG, R. A. (1940), The Practitioner, 144, 434. 